\title{
Structural Parameters Influencing the Shape Memory of New Polymeric Materials Designed for 4D Printing ${ }^{\dagger}$
}

\author{
Laura-Nicoleta Dragomir *, Augusta Raluca Gabor, Ștefan-Ovidiu Dima and Doina Dimonie \\ National Institute for Research and Development in Chemistry and Petrochemistry-ICECHIM, 202 Spl. \\ Independenței, 060021 Bucharest, Romania; ralucagabor@yahoo.com (A.R.G.); \\ phd.ovidiu.dima@gmail.com (Ș.-O.D.); ddiomie@yahoo.com (D.D.) \\ * Correspondence: lauranicoleta.dragomir@gmail.com \\ + Presented at the 16th International Symposium "Priorities of Chemistry for a Sustainable Development" \\ PRIOCHEM, Bucharest, Romania, 28-30 October 2020.
}

Published: 13 November 2020

Keywords: shape memory; polymeric materials

Smart polymeric materials with shape memory are those materials that exist, on a macro scale, in temporary and permanent forms. The transition between these forms is made under the action of external stimuli that generate changes in shape and/or volume and/or color and/or physical properties, etc. [1-2]. The shape memory materials are designed for application in medicine, auto industry, aerospace engineering, etc., and also for academic studies [3]. The paper presents the first results in an attempt to design smart polymeric materials with shape memory for $4 \mathrm{D}$ printing based on polylactic adic (PLA). New PLA-based compounds were achieved in a classical melt compounding Brabender-roller procedure by modification of PLA with a second polymer, synthesized using renewable monomer, for both polymers being considered grades with various chemical structures. A program for the memory setting and highlighting the shape memory property went after that. The memory setting was performed using a DMA instrument Q800 V20.24 Build 43, Module DMA Controlled Force, Inst Serial 0800-1017, Geometry Rectangular (Length, Width, Thickness), Geometry Factor 0.9378 1/mm 0.0784 1/mm 0.0735 1/ $\mathrm{mm}^{2}$, Size 12.7569/6.8700/1.9800 mm, Samples Parameters 0.4400 . The highlighting of the shape memory property was made by using a thermal route and measuring the dimensional parameters specific to the applied procedure.

The behavior at the memory's setting stage depends on the structure of the macromolecules of the two polymers that have been melt compounded (Figure 1). The measurement of the length of each sample with set memory before and after the thermal procedure, applied after the memory setting, varies depending on the chemical structure of the melt compounded polymers.
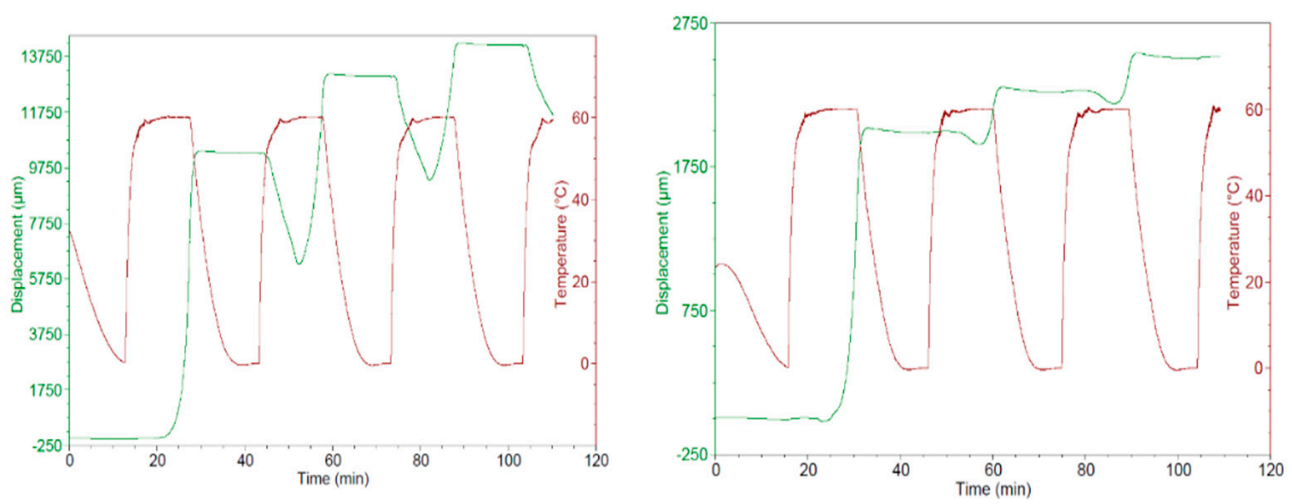

Figure 1. Behavior at the memory's setting stage of two new compounds. 
Studies on designing smart materials with the shape memory for 3D-4D printing will continue. The deepening correlation between the chemical and morphological characteristics of the compounded polymers and the behavior of the new compounds during the two procedures for memory's setting and recovering will be further studied.

Acknowledgments: This work has been founded by Executive Unit for Financing Higher Education, Research, Development and Innovation(UEFISCDI) through project no. PN.19.23.03.02.01.

\section{References}

1. Gonzalez-Henriquez, C.M.; Sarabia-Vallejos, M.A.; Rodriguez-Hernandez, J. Polymers for additive manufacturing and 4d-printing: Materials, methodologies, and biomedical applications. Prog. Polym. Sci. 2019, 94, 57-116.

2. Khoo, Z.X.; Teoh, J.E.M.; Liu, Y.; Chua, C.K.; Yang, S.; An, J.; Yeong, W.Y.; Leong, K.F. 3D printing of smart materials: A review on recent progresses in 4D printing. Virtual Phys. Prototyp. 2015, 10, 103-122.

3. Maria, R.; Aguilar; Roman, J.S. Smart Polymer and Their Application; Woodhead Publishing: Cambridge, UK, 2014.

Publisher's Note: MDPI stays neutral with regard to jurisdictional claims in published maps and institutional affiliations.

() 2020 by the authors. Licensee MDPI, Basel, Switzerland. This article is an open access article distributed under the terms and conditions of the Creative Commons Attribution (CC BY) license (http://creativecommons.org/licenses/by/4.0/). 